\title{
Surgical treatment of mitral valve insufficiency by valve repair
}

\author{
Plastia valvar no tratamento cirúrgico da insuficiência mitral
}

Henrique MURAD, Eliane Carvalho GOMES, Adriana Alves PINHEIRO,José Augusto de AZEVEDO, Mauro Paes Leme de SÁ, André Prado NORONHA, Eduardo Sergio BASTOS, Rubens GIAMBRONI FILHO

\section{Abstract}

Objective: To analyze the short term results of mitral valve repair in a consecutive series of mitral insufficiency patients from different ethiologies.

Methods: A retrospective study was made of 86 patients with mitral insufficiency operated on between May 1992 and May 2001 for mitral valve repair. Mitral insufficiency was severe in 77 patients and moderate in 9 . The functional class of the patients was I in 4, II in 48, III in 29 and IV in 5 patients. The etiology was rheumatic in $47(54.6 \%)$ cases.

Results: Mitral valve repair was performed by only one procedure on the mitral valve in 6 patients, two procedures in 29, and three or more procedures in $51(59.3 \%)$ patients. Mitral annuloplasty was performedin 81 patients, with the Braile posterior pericardial ring being the mostcommonly used $(87.2 \%)$. Hospital mortality was $3.5 \%$. There was improvement in the funcional class in $79(91.8 \%)$ patients. Mitral valve function was normal in $80(93 \%)$ patients and moderate mitral insufficiency occurred in 6 patients.

Conclusion: Mitral valve repair can be performed with low mortality $(3.5 \%)$ and high probability of valve function recovery $(93 \%)$. It should be the procedure of choice in patients with mitral insufficiency.

Descriptors: Mitral valve insufficiency, surgery. Mitral valve, surgery.

\section{Resumo}

Objetivo: Avaliar os resultados, a curto prazo, da plastia valvar mitral em uma série consecutiva de pacientes portadores de insuficiência mitral de etiologia variada.

Método: Foi realizado estudo retrospectivo de 86 pacientes submetidos a plastia valvar mitral, operados entre maio de 1992 e maio de 2001. A insuficiência mitral era grave em 77 pacientes e moderada em 9. A classe funcional era I em 4 pacientes, II em 48, III em 29 e IV em 5. A etiologia era reumática em $47(54,6 \%)$ casos.

Resultados: A reconstrução da valva mitral foi realizada por meio de um único procedimento, em 6 pacientes, dois procedimentos em 29, e três ou mais procedimentos em 51 $\mathbf{5 9 , 3 \%}$ ) pacientes. Anuloplastia mitral foi utilizada em 81 pacientes, sendo o anel de Braile utilizado em $75(87,2 \%)$ deles. A mortalidade hospitalar foi de 3,5\%. Houve melhora da classe funcional em $79(91,8 \%)$ pacientes. A valva mitral ficou normo-funcionante em $80(93 \%)$ pacientes, tendo 6 pacientes ficado com insuficiência mitral moderada.

Conclusão: A plastia valvar mitral pode ser realizada com baixa mortalidade $(3,5 \%)$ e alta probabilidade de recuperação funcional valvar mitral (93\%), devendo ser o procedimento de eleição a ser realizado nos pacientes com insuficiência mitral.

Descritores: Insuficiência da valva mitral, cirurgia. Valva mitral, cirurgia. 


\section{INTRODUCTION}

Several surgical techniques were incorporated in the therapeutic armory for the correction of mitral valve insufficiency, with varying results (Merendino; McGoon; Wooler; Reed; Kay and others). The advent of valvular prosthesis in 1961 seemed to offer a better manner to treat patients with mitral insufficiency. However, the long-term results were disappointing, both using biological and mechanical prosthesis, which encouraged a return to mitral valvuloplasties.

When CARPENTIER in 1983 [1] published his work reporting results accumulated over ten years of mitral valvuloplasty, it appeared to be an adequate form of mitral valve treatment. His results in relation to survival, the appearance of thrombosis, endocarditis or reoperation were better than those obtained by valve replacement. This belief solidified with the publications of the Carpentier group showing the excellent results after 30 years (DELOCHE et al. [2]).

With mitral valvuloplasty, reconstruction of the valve was attempted. It is more important to obtain a functional reconstruction, even if an anatomic reconstruction is not achieved. The technique of mitral valve plasty is also called mitral valvuloplasty, valve reconstruction, valve preservation and valve repair.

Several other surgical techniques were incorporated with those developed by Carpentier and have also been used and include: DURAN \& UBAGO [3], COSGROVE \& STEWART [4], FRATER et al. [5], GREGORI et al. [6] and ALFIERI [7].

The medium- and long-term outcomes of mitral valvuloplasty depend on the quality of the valve repair attained. Patients without mitral valve insufficiency in the immediate post-operative period have a better long-term result. Only the immediate surgical results of mitral valvuloplasty were studied here.

The objectives of this investigation were to determine:

1) The hospital mortality after mitral valvuloplasty;

2) The probability of functional recuperation of the valve after mitral valvuloplasty using the techniques proposed by Carpentier and others.

\section{METHOD}

A retrospective study of 86 patients suffering from mitral insufficiency or double mitral lesion with predominance of insufficiency submitted to mitral valvuloplasty at the University Hospital of Clementino Fraga Filho, Rio de Janeiro and the São Vicente de Paulo was made in the period from May 1992 to May 2001. All the patients were operated on directly by the main author or under his supervision. The data was obtained by an analysis of the surgical patient report cards.
The ages of patients with congenital mitral insufficiency ranged from one to five years and the other patients varied from seven to seventy with an average age of 35.8 years. Table 1 demonstrates the pre-operative clinical data.

Table 1. Clinical data of the patients suffering from mitral insufficiency who underwent mitral valvuloplasty.

\begin{tabular}{llcc}
\hline Clinical Data & & N & \% \\
\hline Gender & Male & 40 & 46.5 \\
& Female & 46 & 53.5 \\
Functional Class & I & 4 & 4.6 \\
& II & 48 & 55.8 \\
& III & 29 & 33.7 \\
Atrial fibrillation & IV & 5 & 5.8 \\
Associated valve diseases & & 15 & 17.4 \\
& Tricuspid & 6 & 7.0 \\
Urgency/Emergency & Aorta & 10 & 11.6 \\
& Others & 4 & 4.6 \\
& & 7 & 8.1 \\
\hline
\end{tabular}

Mitral valvuloplasty was more commonly performed on rheumatic patients (Table 2). In the cases of congenital mitral insufficiency, split cuspids, network valve and congenital mitral ring dilation were included. Partial or total endocardial coxim were not included as a completely different philosophy of treatment is used for its treatment.

Table 2. Mitral insufficiency etiology

\begin{tabular}{lcc}
\hline Etiology & n & \% \\
\hline Rheumatic disease & 47 & 54.6 \\
Degenerative disease & 28 & 32.5 \\
Congenital & 6 & 7.0 \\
Endocarditis & 2 & 2.4 \\
Ischemic & 2 & 2.4 \\
Cardiomyopathy & 1 & 1.2 \\
\hline
\end{tabular}

The distinction between myxomatosis degeneration (Barlow's disease) and fibroelastic degeneration has only recently started being determined. Myxomatosis degeneration is characterized by excess of tissue in the cuspids, whilst fibroelastic degeneration is characterized by tissue fragility with stretching or rupture of the chordae tendineae. For the effect of this study, these two nosologic entities were grouped under the denomination of mitral valve degenerative diseases.

Mitral insufficiency was moderate in nine (10.5\%) of the patients and severe in $77(89.5 \%)$.

Hospital mortality was analyzed and assessment of the mitral valve function was made on the 30 th post-operative day by means of transthoracic echocardiogram. 


\section{RESULTS}

There was no intra-operative mortality in patients submitted to mitral valvuloplasty.

The hospital mortality was 3.5\% (three patients). One of them died as a consequence of a cardiopulmonary bypass complications with aerial emboli. Another with multiple organ failure and the third with sepsis subsequent to a ruptured duodenal ulcer after the patient was already in the ward. There were two late deaths, one due to heart failure and the other due to arrhythmia.

The intra-operative pathological findings are shown in Table 3 and the surgical procedures performed in Table 4.

With mitral valvuloplasty, the aim is to correct all the anatomic alterations found.

A single procedure was performed on $6(7 \%)$ of the patients, two procedures on $29(33.7 \%)$ and three or more procedures on $51(59.3 \%)$ of the individuals.

Associated aortic valve replacement was performed on $29(33.7 \%)$ patients and tricuspid valvuloplasty on six patients.

In the echocardiography performed 30 days after the surgery, the mitral valve was competent in $93 \%$ of the patients submitted to mitral valvuloplasty (Table 5). There were only six cases of moderate mitral valve insufficiency in the early postoperative period, where two of them eventually required mitral valve replacement. There was

Table 3. Intra-operative pathologic findings.

\begin{tabular}{|c|c|c|c|}
\hline & & $\mathrm{n}$ & $\%$ \\
\hline \multirow[b]{2}{*}{ Mitral ring } & increased & 76 & 88.4 \\
\hline & normal & 9 & 10.5 \\
\hline \multicolumn{4}{|c|}{$------------\frac{\text { calcified }}{\text { thick }}$} \\
\hline \multirow{7}{*}{ Cuspid } & posterior prolapsed & 37 & 43 \\
\hline & anterior prolapsed & 31 & 36 \\
\hline & split & 5 & 5.8 \\
\hline & calcified & 3 & 3.5 \\
\hline & perforated & 2 & 2.3 \\
\hline & rupture (balloon) & 1 & 1.1 \\
\hline & vegetation & 1 & 1.1 \\
\hline \multirow{3}{*}{-----------} & Barlows syndrome & 1 & 1.1 \\
\hline & Anterior stretch & $5 \overline{7}$ & $6 \overline{6} . \overline{2}$ \\
\hline & posterior direction & 30 & 34.8 \\
\hline \multirow{4}{*}{ chordae tendineae } & anterior direction & 24 & 27.9 \\
\hline & posterior retraction & 15 & 17.4 \\
\hline & anterior retraction & 11 & 12.7 \\
\hline & posterior stretch & 9 & 10.5 \\
\hline--------- & fusion $-{ }_{-}-\ldots$ & $\frac{6}{50}$ & -7.0 \\
\hline Movement of the cuspids & $\begin{array}{l}\text { increased } \\
\text { reduced }\end{array}$ & $\begin{array}{l}50 \\
32\end{array}$ & $\begin{array}{l}58.1 \\
37.2\end{array}$ \\
\hline--------- & normal $-\cdots$ & $-\frac{4}{85}$ & $4 . \overline{8} \overline{8}$ \\
\hline Papillary muscle & ischemic & 1 & 1.1 \\
\hline Cómmissüre- & $\overline{\text { Fusi on }}--$ & $2 \overline{4}$ & $2 \overline{7} . \overline{9}$ \\
\hline
\end{tabular}

Table 4. Surgical procedures for mitral valvuloplasty

\begin{tabular}{|c|c|c|c|}
\hline & & $\mathrm{n}$ & $\%$ \\
\hline \multirow{3}{*}{ mitral ring } & Brailes ring & 75 & 87.2 \\
\hline & none & 5 & 5.8 \\
\hline & Carpentiers ring & 5 & 5.8 \\
\hline \multirow{3}{*}{---------} & Gregoris ring & 1 & 1.1 \\
\hline & quadrangular resection & $\overline{2} 8$ & $3 \overline{2} .5$ \\
\hline & posterior cuspid extension & 13 & 15.1 \\
\hline \multirow[t]{4}{*}{ Cuspids } & sliding & 9 & 10.5 \\
\hline & secondary to primary cord & 7 & 8.1 \\
\hline & split suture & 5 & 5.8 \\
\hline & patch $\ldots$ & 2 & 2.3 \\
\hline \multirow{2}{*}{--------} & transference- - & 16 & $1 \overline{8} .6$ \\
\hline & trenching & 15 & 17.4 \\
\hline \multirow[t]{2}{*}{ chordae tendineae } & chord resection & 11 & 12.8 \\
\hline & neo -chord & 10 & 11.1 \\
\hline$\overline{\text { commissurotomy }}-\overline{-}$ & fenestration ---- & $\frac{5}{24}-$ & $\begin{array}{r}5.8 \\
-2 \overline{7} .9\end{array}$ \\
\hline papilectomy & & 7 & 8.1 \\
\hline cal cium debridement & & 7 & 8.1 \\
\hline ring decalcification & & 1 & 1.1 \\
\hline
\end{tabular}

Table 5. Post-operative echocardiograph variations.

\begin{tabular}{llcc}
\hline Echocardiograph data & & n & \% \\
\hline Mitral insufficiency & absent & 47 & 54.6 \\
& mild & 33 & 38.4 \\
& moderate & 6 & 7.0 \\
& severe & 0 & - \\
Slight mitral stenosis & & 1 & 1.1 \\
\hline
\end{tabular}

one case of slight mitral stenosis after mitral valvuloplasty due to excessive correction (an infant with rheumatic disease). As we considered that this evaluation was too early, the function and the ventricular diameters were not measured.

Mitral valve functional recovery (absent or mild mitral valve insufficiency) occurred in $93 \%$ of the patients who underwent mitral valvuloplasty. This was made up of $83.3 \%$ of the rheumatic sufferers and $96.4 \%$ of the degenerative disease patients. Of the 47 patients with rheumatic disease, five presented with moderate mitral insufficiency in the postoperative period and of the 28 degenerative disease patients only one had moderate mitral insufficiency in the postoperative period.

Mitral valvuloplasty was not performed in patients with calcification of the cuspids or in reoperations after mitral valvuloplasty failure. Urgent and emergency operations or when an associated surgical procedure (valvar or coronary) was necessary, mitral valvuloplasty was not contra- 
indicated. Also acute endocarditis was not considered as a contra-indication for mitral valvuloplasty, although in this series only one patient presented with this condition. Only one patient underwent mitral annulus decalcification too.

In one patient the mitral valve replacement was performed after a failed attempt of mitral valvuloplasty. A pre-operative trans-esophagus echocardiogram was performed in $4 \%$ of the patients.

Mitral valve surgery, either plasty or valve replacement, in dilated cardiomyopathy, is still in the study phase. One case of valvuloplasty was operated on obtaining an improvement of the symptoms.

\section{COMMENTS}

Results of mitral valvuloplasty have been superior to mitral valve replacement. The operative mortality in this series was $3.5 \%$ for mitral valvuloplasty. MUEHRCKE \& COSGROVE [8] compared a collection of 1,025 cases of mitral valvuloplasty and 1,064 cases of mitral valve replacements obtained from ten recently published investigations. They found an average operative mortality rate of $3.8 \%$ (ranging from 0 to $6.1 \%$ ) for mitral valvuloplasty and a mean of $6.9 \%$ (ranging from 3.0 to $18.1 \%$ ) for mitral valve replacement. ENRIQUEZ-SARANO et al. [9] in 1995 demonstrated an improved survival rate and lower incidence of valve-related complications with mitral valvuloplasty compared to valve replacement.

The cardiopulmonary bypass time and the aorta clamping time are greater for mitral valvuloplasty than for mitral valve replacement. In spite of this greater time, the mortality rate is lower in mitral valvuloplasty. This is partly due to the maintenance of the ventricular geometry and partly because prosthesis-related complications are avoided, such as paravalvar leakage, disc obstruction, endocarditis, etc.

The main objective of mitral valvuloplasty is to obtain a normally functioning mitral valve, that is, without stenosis or insufficiency. It is necessary to correct all the anatomic alterations that lead to mitral insufficiency to obtain a stable result. On the other hand, when the result achieved with mitral valvuloplasty does not manage to make the valve function normally, there is a high incidence of valve replacement in the future. There were six patients who were released from hospital with moderate mitral insufficiency. Two have already undergone valve replacement, three do not have the criteria for valve replacement yet and the sixth, who suffered from congenital mitral valve insufficiency with a hammock valve, passed away before reoperation.

It is important for the surgeon to decide case-by-case as to the best strategy, mitral valvuloplasty or replacement. Pure annular dilatation or rupture of the chordae tendineae of the posterior cuspid has a highly favorable surgical result. As experience is gained it is possible that more patients benefit from mitral valve repair.
The surgical result varies with the possibility of repairing all the anatomical lesions encountered. It also varies with the etiology of the mitral valve insufficiency.

Dilation of the mitral annulus occurs in almost all patients with mitral insufficiency. CARPENTIER [1] believes that it is important to remodel the mitral annulus to achieve a good long-term result. DELOCHE et al. [2] demonstrated an excellent durability of mitral valvuloplasty using Carpentier's technique with only $6.2 \%$ of the patients who underwent surgery for degenerative disease requiring valve replacement within the first 20 years after surgery. On the other hand, some authors such as KALIL et al. [10] considered mitral valvuloplasty unnecessary. POMERANTZEFF et al. [11] used the procedure selectively. We used mitral valvuloplasty in nearly all cases, as suggested by Carpentier. The implanted ring gives stability to the performed plasty, impeding future dilations of the posterior cuspid.

Carpentier's classical ring is rigid with an anterior opening to enable its adaptation to the mitral annulus. The advantage of this ring is the remodeling obtained, exchanging the greater transversal axis for the anteroposterior. DURAN \& UBAGO [3] introduced a flexible circular ring, which has the advantage of homogenous distribution of the tension at which the sutures are submitted and a greater flexibility of the mitral annulus during the cardiac cycle, allowing a certain amount of constriction. Posterior annuloplasty is preferred, as it is faster and simpler. The basis for this is the concept that only the posterior part of the annulus dilates, and thus there is no necessity to fix the anterior part. Because of this, anchoring of the posterior ring between the fibrous trigones of the heart was utilized (and not between the commissures as recommended by some).

Anterior systolic movement is more common with rigid rings than flexible or posterior rings .

The material used can be Dacron, as propounded by COSGROVE \& STEWART [4], or autologous or bovine pericardium as proposed by BRAILE et al. [12]. We used bovine pericardium rings as they are as efficient as Dacron and the cost is lower. In re-operated patients, degeneration of the pericardium was not encountered, which becomes uniformly covered with atrial endothelium.

In patients with dilated cardiomyopathies in which an accentuated reduction of the mitral annulus is planned in order to obtain a greater apposition to the cuspids it is important to use either a rigid (Carpentier) or a flexible (Duran) circular ring. In this case the forces of tension should be distributed around the circumflex of the ring.

Summarizing, there are still arguments to defend the use of all types of rings, with preference for the posterior flexible ring. No advantages of Gregori's rigid posterior ring over the bovine pericardial flexible rings were evidenced.

In this trial, a bovine posterior ring was employed in 75 $(87.2 \%)$ surgeries and Carpentier's ring in 5 (5.8) cases. Generally, in the cases with congenital mitral insufficiency, 
a ring was not used due to the necessity of future growth. A bovine pericardial ring was utilized in only one child with a great dilation of the valvular annulus and the circumference of the mitral annulus close to that of an adult.

Among procedures performed on cuspids, quadrangular resection of the posterior leaflet, commissurotomy and hole closure using a pericardial patch are widely accepted. The sliding technique, described by CARPENTIER [1], was used to solve the problem of an excess of valvar tissue in Barlow's syndrome and the appearance of SAM (forward systolic movement of the anterior cuspid of the mitral valve with obstruction of the left ventricle outflow tract). This sliding technique is useful in situations in which there is rupture of posterior chordae tendineae near the commissures $\left(\mathrm{P}_{1}\right.$ or $\mathrm{P}_{3}$ ): quadrangular resection is performed and the cuspid is slid and the commissure is remade. This sliding technique was utilized in $10.5 \%$ of the patients, always associated with other procedures.

With rheumatic disease, one problem, which makes mitral valvuloplasty very difficult in cases with double mitral lesions, is the retraction of the posterior cuspid. These authors and others have already tried resection of the secondary chordae of the posterior cuspid, even with removal of the posterior cuspid but with little success. CHAUVAUD et al. [13] in 1991, developed, for these cases, the concept of posterior cuspid extension with autologous pericardium preserved in glutaraldehyde. This technique was used in 13 patients, employing an incision along all the extension of the cuspid, amplifying it with a bovine pericardial patch. We achieved a good functioning of the mitral valve in rheumatic patients. Calcification of the cuspids has been a contra-indication for mitral valvuloplasty for the majority of surgeons. This was also our conduct. CARPENTIER [1] and GROSSI et al. [14] have treated these patients aggressively with decalcification of the cuspids attaining good results.

Calcification of the mitral valve is a complicated problem to solve. CARPENTIER et al. [15] proposed making an incision in the mitral annulus and removing the whole calcium block, stimulating a dislodgment of the ventricular atrium. Following this, the left atrium is reinserted in the left ventricle and the posterior cuspid is reinserted on this suture line which represents a posterior neo-annulus.

The prolapse, or rupture of the chordae tendineae of the anterior cuspid might by treated by transferring chords. Excellent results were obtained by LESSANA et al. [16] employing this technique: $97 \%$ of their 39 patients were free of reoperations four years after the surgery. For the prolapse of the anterior leaflet, another technique which is used is trenching where an incision is made in the papillary muscle and the excess of chords are inserted inside. SMEDIRA et al. [17] in 1996, compared the trenching of chords of 31 patients with transference of chords in 77 individuals and obtained absence of reoperation in $74 \%$ in the first group and $96 \%$ in the second five years after the surgery. The reason for failure in the chord trenching group was rupture of the chord at the insertion point of the papillary muscle. Similar findings have been found comparing neo-chords of PTFE with the trenching technique (PHILLIPS et al. [18], 2000). Our preference has been firstly, transference of the chords; secondly, trenching of the chords; thirdly, neo-chord of PTFE. We have also used (four times with good results) PTFE threads to reinforce chords in other places in patients in whom trenching of the chordae tendineae was made.

The technique of chordae tendineae substitution by PFTE was made popular by FRATER et al. [5] in 1990. These threads did not calcify and over the long term, were completely covered by fibrous tissue. They are resistant and, in reoperations, seem like normal chordae. The incidence of thromboembolism and infection is low. We used this technique in $10(11.1 \%)$ of the cases.

Other procedures can be used to compliment the techniques developed by Carpentier. GREGORI et al. [6] published three techniques for the anterior cuspid chordae tendineae rupture. We used one of these techniques in which a small incision is made in the thick portion of the anterior cuspid near to the free edge, close to the origin of the elongated chordae. The elongated chordae is pulled through this incision at the desired level and fixed with the sutures used to close the incision.

Another technique utilized is to suture the anterior and posterior cuspid in the prolapsed or ruptured region. This technique, made popular by ALFIERI [7] (2000), transforms the mitral valve into a valve with two openings, but there is the risk of provoking mitral stenosis. We only used this once in a patient who, at the end of mitral valvuloplasty, continued to present with a small area of anterior prolapse. We successfully joined this area of the anterior cuspid to another adjacent to the posterior cuspid.

The surgeon needs to have in mind all the possibilities to be used. Frequently he has to use several techniques in one specific case. In our cases, we used three or more procedures in $59.3 \%$ of the cases.

Mitral valvuloplasty can be used with other associated surgical procedures: aortic valve replacement, coronary arterial bypass grafting and tricuspid valvuloplasty. In spite of longer times of cardiopulmonary bypass and aortic clamping, the best results of mitral plasty over those of mitral valve replacement justify the effort. In one of our patients, a child with aortic insufficiency, functional class IV mitral and tricuspid, we successfully performed mitral valvuloplasty, tricuspid valvuloplasty, and aortic valve replacement with an aortic homogenous graft. Despite the extended times of the surgery, the result of class I was excellent.

The surgical treatment of simultaneous atrial fibrillation with mitral valvuloplasty is very controversial. With the surgery of Cox, the Maze III technique, we have a long and 
laborious surgery, and is acceptable only in patients who need relatively simple and quick plasties.

The long-term results are worse in rheumatic patients than in patients with degenerative disease. DELOCHE et al. [2] in 2001, encountered that in 25-year post-mitral valvuloplasty only $40 \%$ of rheumatic disease patients were free of reoperation, against $9 \%$ of degenerative disease patients.

Although, over the long term, rheumatic disease patients have had a high incidence of reoperation, the work of DELOCHE et al. [2] in 2001 demonstrated that in these patients a 20-year survival rate of $90 \%$ and over 25 years of $75 \%$. What is tempting about performing mitral valvuloplasty in rheumatic disease patients are the low rates of thromboembolism or accidental hemorrhage, endocarditis and valve-related mortality.

In degenerative disease, the indication of mitral valvuloplasty is unquestionable. COHN et al. [19] in 1994, reported operative mortality of $2.3 \%$ and a survival curve over five years of $86 \%$; with $97 \%$ free of endocarditis; $94 \%$ free of thromboembolism and $83 \%$ free of structural deterioration.

Our functional recovery incidence of the mitral valve was of $96.4 \%$ and $89.3 \%$ with degenerative disease and rheumatic disease respectively. BARBOSA et al. [20] obtained mitral valve functional recovery in $80 \%$ of their 82 operated rheumatic patients.

In congenital mitral insufficiency, the valvuloplasty depends on the involved mechanism. It can be extremely difficult, as in the valves on the network, or simple, as in the valvular breeches. It is difficult to study the group as a whole due to the differences in the diseases found.

In acute endocarditis, the first aim of the surgeon is debridement of all the infected tissue. When, after debridement there is a possibility of mitral valve repair, it should be performed. With valvuloplasty, the subvalvar apparatus is preserved and the native valve tissue remains which is more resistant to re-infection than a prosthesis. Apart from this, in the aftermath of endocarditis, mitral valve replacement has a high incidence of problems: re-infection, perivalvular leakageand thromboembolism. We managed to perform valvuloplasty in only one patient with acute endocarditis: we sutured a pericardial patch, transferred chordae and implanted a ring. This patient presents with functional class I with normal sized left ventricle and only with moderate mitral valve insufficiency six years after surgery. PAGANI et al. [21] in 1996, showed a greater possibility of reconstruction in cured endocarditis with the liberal use of autologous pericardium.

Ischemic mitral insufficiency can be difficult to repair. It can be secondary to ischemia or rupture of the papillary muscles, the ischemic or fibrous alterations of the left ventricular musculature that sustains the papillary muscles or secondary to annular dilation, ischemic cardiomyopathy.
In the acute cases we prefer to replace the mitral valve. In the chronic cases we perform a plasty directed to the existent problem. In the cases of dilated annulus or restriction to the movement of the leaflets, we placed a relatively small closed ring to increase the coaptation area of the cuspids. It may be necessary to place the ring in a relatively eccentric position to compensate the area corresponding to the ischemic, fibrous or elongated papillary muscles. In the cases with valvular prolapse, we corrected the presented defects in a conventional way. Coronary artery bypass grafting should be performed in all cases. We performed only two valvuloplasties for ischemic disease.

Recently, BOLLING [22] in 2000, suggested treating mitral insufficiency in cardiomyopathy patients by placing a small mitral ring, increasing the surface contact of the cuspids in these large volume hearts. He managed to greatly improve the symptoms and a slight improvement in the survival when compared to clinical treatment. We performed this operation in only one patient.

The result of mitral valvuloplasty over the medium-term and long-term, depends on the quality of repair achieved. The best method of evaluation is by means of per-operative trans-esophagus echocardiogram. Moderate mitral insufficiency at the end of the surgery should be treated by a new plasty or mitral valve replacement. Unhappily, we only used trans-esophagus echocardiogram in $4 \%$ of the procedures, due to hospital difficulties. At the end of the surgery, we tested the competence of the mitral valve by the injection of a physiological serum under pressure in the left ventricle.

FIX et al. [23] in 1993, reported that patients who presented with light to moderate mitral insufficiency in the post-operative period, had morbidity and mortality rates similar to a group of patients without post-valvuloplasty mitral insufficiency. However, the incidence of reoperation at a four-year follow-up was $17 \%$ in the residual mitral insufficiency group against $6 \%$ in the group without residual mitral insufficiency. It thus becomes important to have precise information about the state of mitral valve functioning after the valvuloplasty. The trans-esophagus echocardiogram is a valuable ally to obtain this information.

It is possible to predict with great certainty, which patients will benefit for sure from mitral valvuloplasty and in which it can be performed. Patients with annular dilation, degenerative disease and prolapse or rupture of $1 / 3$ of the posterior cuspid are the best candidates for mitral valvuloplasty with low morbidity and mortality rates and a high probability of a normal mitral function over the long term. These results depend much on the surgeon's experience. SOUZA-UVA et al. [24] in 1996, based on these premises advocated the surgical treatment of asymptomatic patients with mitral insufficiency in that it is possible to perform valvuloplasty.

The result of mitral valvuloplasty compares favorably 
with that obtained with mitral valve replacement, using both biological and mechanical prostheses, not only in relation to early and late morbidity but also in relation to thromboembolism, accidental hemorrhage, endocarditis and structural failure of the valve.

In this work we concentrated on the immediate result as the article of FIX et al. [23] shows a great correlation between the immediate and late results.

Recurrence of post-valvuloplasty mitral valve insufficiency is an uncommon complication. In the experience of the Cleveland Clinic, it occurred in 3\% of 2,548 patients due to the progression of primary valvar disease (57\% of the cases), rupture of a chordae after trenching on the papillary muscle, to inadequate initial plasty and leakageof the suture. Mitral valve replacement was performed in $79 \%$ of the patients and a new mitral valvuloplasty in $21 \%$ (GILLINOV et al. [25]).

DELOCHE et al. [2] in 2001, reported that the possibility of a new plasty is $36 \%$ of the cases with degenerative disease and only $6 \%$ of the patients with rheumatic disease. We did not have the opportunity to perform mitral re-valvuloplasty.

\section{CONCLUSIONS}

1) Mitral valvuloplasty can be performed with low mortality rate $(3.5 \%)$, and should be the choice procedure to be used for patients with mitral insufficiency.

Mitral valve functional recovery occurred in $93 \%$ of the patients submitted to mitral plast.

\section{BIBLIOGRAPHIC REFERENCES}

1. Carpentier A. Cardiac valve surgery: the "French correction". J Thorac Cardiovasc Surg 1983; 86:323-37.

2. Deloche A, Carpentier A, Chauvaud S et al. Mitral valve repair with Carpentier's techniques: the third decade. In: $81^{\text {st }}$ Annual Meeting of the American Association for Thoracic Surgery; 2001; San Diego.

3. Duran CG, Ubago JL. Clinical and hemodynamic performance of a totally flexible prosthetic ring for atrioventricular valve reconstruction. Ann Thorac Surg 1976; 22: 458-63.
4. Cosgrove DM, Stewart WJ. Mitral valvuloplasty. Curr Probl Cardiol 1989; 14: 359-415.

5. Frater RW, Vetter HO, Zussa C, Dahm M. Chordal replacement in mitral valve repair. Circulation 1990; 82 (Suppl 5): IV125-30.

6. Gregori Jr F, Silva S, Facanha L, Cordeiro C, Aquino W, Moure O. Preliminary results with a new technique for repairing elongated chordae tendineae of the anterior mitral valve leaflet. J Thorac Cardiovasc Surg 1994;107:321-3.

7. Alfieri O. Mitral valve reconstruction: the double orifice technique video. J Cardio-Thoracic Surgery 2000;15: 3.

8. Muehrcke DD, Cosgrove DM. Mitral valvuloplasty. In: Edmunds Jr LH, ed. Cardiac surgery in the adult. New York: McGraw Hill; 1997. p.991.

9. Enriquez-Sarano M, Schaff HU, Orszulak TA, Tajik AJ, Bailey KR, Frye RL. Valve repair improves the outcome of surgery for mitral regurgitation: a multivariate analysis. Circulation 1995; 91:1022-8.

10. Kalil RA, Lucchese FA, Prates PR, Sant'Anna JR, Faes FC, Pereira E et al. Late outcome of unsupported annuloplasty for rheumatic mitral regurgitation. J Am Coll Cardiol 1993; 22:1915-20.

11. Pomerantzeff PMA, Brandão CMA, Faber CM, Grinberg M, Cardoso LF, Tarasoutchi $\mathrm{F}$ et al. Plástica da valva mitral em portadores de febre reumática. Rev Bras Cir Cardiovasc 1998; $13: 211-5$.

12. Braile DM, Ardito RV, Pinto GH, Santos JLV, Zaiantchick M, Souza DRS et al. Plástica mitral. Rev Bras Cir Cardiovasc 1990; 5:86-98.

13. Chauvaud S, Jebara V, Chachques JC, el Asmar B, Mihaileanu $\mathrm{S}$, Perier Pet al. Valve extension with glutaraldehyde-preserved autologous pericardium: results in mitral valve repair. J Thorac Cardiovasc Surg 1991; 102:171-8.

14. Grossi EA, Galloway AC, Steinberg BM, LeBoutillier M 3rd, Delianides J, Baumann FG et al. Severe calcification does not affect long-term outcome of mitral valve repair. Ann Thorac Surg 1994; 58:685-8.

15. Carpentier AF, Pellerin M, Fuzellier JF, Relland JY. Extensive calcification of the mitral valve annulus: pathology and surgical management. J Thorac Cardiovasc Surg 1996; 111:718-30.

16. Lessana A, Carbone C, Romano M, Palsky E, Quan YH, Escorsin $\mathrm{M}$ et al. Mitral valve repair: results and the decisionmaking process in reconstruction. Report of 275 cases. J Thorac Cardiovasc Surg 1990; 99:622-30.

17. Smedira NG, Selman R, Cosgrove DM, McCarthy PM, Lytle BW, Taylor PC et al. Repair of anterior leaflet prolapse: chordal transfer is superior to chordal shortening. J Thorac Cardiovasc Surg 1996; 112:287-92. 
18. Phillips MR, Daly RC, Schaff HV, Dearani JA, Mullany CJ, Orszulak TA. Repair of anterior leaflet mitral valve prolapse: chordal replacement versus chordal shortening. Ann Thorac Surg 2000; 69:25-9.

19. Cohn LH, Couper GS, Aranki SF, Rizzo RJ, Kinchla NM, Collins Jr. JJ. Long-term results of mitral valve reconstruction for regurgitation of the myxomatous mitral valve. J Thorac Cardiovasc Surg 1994; 107:143-51.

20. Barbosa GV, Saadi JF, Wender OCB, Saadi EK, Dussin LH, Silva RK. Plastia na insuficiência mitral reumática. Arq Bras Cardiol 69 (Suplemento I): 180, 1997.

21. Pagani FD, Monaghan HL, Deeb GM, Bolling SF. Mitral valve reconstruction for active and healed endocarditis. Circulation 1996; 94 (9 Suppl): II133-8.
22. Bolling SF. Ventricular remodelling following mitral annuloplasty Video. J Cardio-thoracic Surg 2000; 14:4.

23. Fix J, Isada L, Cosgrove D, Miller DP, Savage R, Blum J et al. Do patients with less than "echo-perfect" results from mitral valve repair by intraoperative echocardiography have a different outcome? Circulation 1993; 88 (5 Pt 2):II39-48.

24. Sousa Uva M, Dreyfus G, Rescigno G, al Aile N, Mascagni R, La Marra M, et al. Surgical treatment of asymptomatic and mildly symptomatic mitral regurgitation. J Thorac Cardiovasc Surg 1996; 112:1240-9.

25. Gillinov AM, Cosgrove DM, Lytle BW, Taylor PC, Stewart RW, McCarthy PM et al. Reoperation for failure of mitral valve repair. J Thorac Cardiovasc Surg 1997; 113:467-75. 